\title{
STUDI KEANEKARAGAMAN KUPU-KUPU DI BANTARAN \\ SUNGAI BATANGHARI KOTA METRO SEBAGAI SUMBER BELAJAR BIOLOGI MATERI KEANEKARAGAMAN
}

\author{
Rasuane Noor \\ Suharno Zen \\ Pendidikan Biologi FKIP Universitas Muhammadiyah Metro \\ E-mail: rasuanenoor@gmail.com, suharnozein@gmail.com
}

\begin{abstract}
Butterflies are insects that have a very important role in the ecosystem is as a helper in the pollination in plants. In addition butterfly can also be used as a bioindicator to changes in environmental quality since butterflies are very sensitive to changes in the ecosystem. The existence of butterflies are under threat at this time step and extinction, this is due to the many forests are converted into other land. Diminishing forests and lands turned into settlement and agriculture. Butterfly existence will depend habitat. Butterfly habitat with the amount of food available is quite the diversity of butterflies is high.

The aim of research to determine the diversity of butterflies in Batanghari River Plate in Metro City, the research method used is survey method with purporsive sampling. Butterfly collection done by sweeping follows the line transect technique is applied randomly along the $1000 \mathrm{~m}$. After completion of the identification process we then held classification process. Species diversity index $(H)$ is calculated using the Shannon-Wiener formula. Results of the study found as many as 23 species of butterflies of 5 familia, with the most dominant species is Eurema alitha as much as 136. The diversity of butterflies in the Batanghari River Plate in City Metro categorized bit or lower because it has the value $H 1<1$.
\end{abstract}

Kata Kunci ; Kupu-kupu, keanekaragaman, sungai batanghari.

Kupu-kupu

merupakan fauna yang termasuk kelompok serangga yang memiliki peran sangat penting dalam ekosistem yaitu sebagai pembantu dalam penyerbukan pada tumbuhan. Selain itu kupu-kupu juga dapat dijadikan sebagai bioindikator terhadap perubahan kualitas lingkungan karena kupu-kupu sangat sensitif terhadap perubahan ekosistem. Terdapat banyak jenis kupu-kupu dengan ciri khas yang indah dan cantik karena memiliki warna dan bentuk yang menawan. Sehingga memiliki nilai ekonomis yang biasa dijadikan koleksi, bahan pola dan seni (Peggie \& Amir 2006).

Keanekaragaman kupu-kupu di Indonesia belum terdata dengan lengkap termasuk juga yang ada di
Kota Metro. Berdasarkan pendapat Soekardi (2007) di Pulau Sumatera diperkirakan terdapat tidak kurang dari 1.000 spesies kupu-kupu, walaupun data tentang keanekaragaman kupukupu di Sumatera belum lengkap. Di Taman Nasional Way Kambas terdapat 77 spesies, Taman Nasional Bukit Barisan Selatan 185 spesies, dan Taman kupu-kupu Gita Persada, Gunung Betung Lampung 107 spesies. Sedangkan di daerah Sumatera Barat tercatat sekitar 325 spesies (Dahelmi et al. 2010), Di Rokan Hulu Provinsi Riau terdapat 150 spesies kupu-kupu (PEI-Pusat 2011). Di Taman Nasional Kerinci Seblat Jambi terdapat 230 spesies kupu-kupu (Salmah et al. 2002). 
Keberadaan kupu-kupu saat ini terancaman langkah dan kepunahan, hal ini disebabkan sudah banyaknya alih fungsi hutan. Hutan-hutan semakin berkurang dan beralih menjadi lahan-lahan pemukiman dan pertanian. Keberadaaan kupu-kupu tergantung akan habitatnya. Habitat kupu kupu dengan jumlah makanan yang tersedia cukup maka keanekaragaman kupukupu yang tinggi (Thomas et al. 2004). Pada daerah yang dilindungi dan berdekatan dengan hutan alami memiliki jumlah keanekaragaman dan kemerataan spesies di dalam komunitas yang lebih tinggi apabila dibandingkan dengan daerah yang tidak dilindungi dan terpisah dari hutan (Koh dan Sodhi, 2004). Jika disuatu habitat sudah berubah dimana tumbuhan sebagai pakan sudah hilang maka jumlah jenis kupu-kupu akan berkurang. Penyusutan dan perubahan ekosistem hutan yang terjadi karena eksploitasi yang sangat cepat merupakan ancaman bagi keberadaan kupu-kupu.

Sundufu dan Dumbuya (2008) menyatakan bahwa jumlah kupu-kupu terbanyak ditemukan di hutan lindung, hutan, hutan yang sudah diolah, dan padang rumput. Di lingkungan perkebunan ataupun sekitar hutan akan mudah sekali menemukan kupu-kupu dengan berbagai jenis dan corak yang khas, selain itu sepanjang aliran sungai akan banyak sekali menemukan jenisjenis kupu-kupu karena kupu-kupu membutuhkan air untuk minum. Dari prasurvei ke lokasi sungai Batanghari yang melintasi kota Metro, masih banyak ditemukan pohon-pohon dan tumbuhan liar sehingga lokasi ini sangat cocok untuk habitat kupu-kupu di sekitar tersebut.

Metro merupakan salah satu kota terbesar di propinsi Lampung terus giat dalam penggalakan peningkatan kualitas sumber daya hayati, sebagai bukti Metro menjadi salah satu kota terhijau di Indonesia. Tidak kalah pentingnya Kota Metro sebagai kota pendidikan berupaya pengembangkan wilayahnya menjadi media pembelajaran bagi masyarakatnya termasuk keberadaan flora dan faunanya. Hal ini adalah bagian dalam kerangka pembangunan berkelanjutan khususnya pendidikan yang menanamkan konsep pemanfaatan dan pelestarian keanekaragaman hayati. Seiring dengan pendapat Subahar \& Yuliana (2010) Kupu-kupu dapat pula menjadi bahan pelajaran untuk kepentingan studi ilmiah, sehingga Keanekaragaman Kupu-kupu di Pinggiran Sungai Batanghari Metro Sebagai Sumber Belajar Materi Keanekaragaman perlu dilakukan. Untuk itu sebelum kita kehilangan keanekaragaman hayati khususnya kupu kupu, maka Studi keanekargaman kupu-kupu tersebut sangat penting sebagai data dasar keanekaragaman hayati dan bahan pertimbangan dalam memformulasikan strategi konservasinya di kota Metro.

\section{METODE}

Pengambilan data lapangan dilaksanakan selama dua bulan yaitu dari bulan Maret sampai April dengan 2015. Lokasi penelitian berada di pinggiran Sungai Batanghari Kota Metro. Metode pengambilan sampel yang digunakan adalah metode survey dengan pengambilan sampel secara purporsive. Koleksi kupu-kupu dilakukan dengan teknik sweeping mengikuti garis transek yang diterapkan secara random sepanjang $1000 \mathrm{~m}$ dan teknik ini telah digunakan lebih dari 25 tahun dan dianggap efektif (Hamer et al., 1997). Pengambilan sampel dilaksanan dari jam 8 sampai 15 WIB (Peggie dan 
Amir, 2006). Proses identifikasi dan klasifikasi spesimen dengan menggunakan buku identifikasi. Setelah selesai proses identifikasi maka selanjutnya diadakan proses pengklasifikasian.

Data disajikan secara kuantitatif dengan parameter Indeks Keanekaragaman Spesies (H), Indeks Keanekaragaman spesies $(\mathrm{H})$ dihitung dengan menggunakan rumus ShannonWiener (Brower et al. 1998), yaitu:

$\left(\mathrm{H}^{\prime}\right)=-\Sigma$ pi log pi

Dimana:

$\mathrm{H}^{\prime}=$ Indeks Keanekaragaman spesies

$\mathrm{pi}=\mathrm{ni} / \mathrm{N}$

pi $=$ Proporsi nilai ke- $\mathrm{i}$

$\mathrm{ni}=$ Jumlah individu spesies ke-i

$\mathrm{N}=$ Jumlah individu semua spesies
HASIL

Sungai Batanghari merupakan salah satu dari 4 sungai yang terdapat di Kota Metro dengan panjang 16,150 Km dan Lebar Permukaan rata-rata 15 meter, Di sepanjang sungai ini banyak ditumbuhi tumbuhan liar dan yang ditanam oleh pemerintah daerah. Tumbuhan liar yang tumbuh di tepi sepanjang sungai ini adalah kelompok rumput-rumputan : ilalang, rumput gajah, senggani, tembelekan, ingas dan lainnya. Sedangkan tumbuhan yang ditanam meliputi : akasia, mahoni, famboyan, bambu, rumput ilalang, rumput gajah dan lain-lainnya. Hasil Penelitian yang tertera dalam tabel 1.

Tabel 1. Jumlah Spesies Kupu-Kupu Ditemukan di Bataran Sungai Batanghari

Kota Metro

\begin{tabular}{|c|c|c|c|c|c|c|c|c|c|c|c|c|}
\hline \multirow[t]{2}{*}{ No } & \multirow[t]{2}{*}{ Spesies } & \multicolumn{10}{|c|}{ Jumlah spesies setiap Stasium } & \multirow{2}{*}{$\begin{array}{c}\text { Jmlh } \\
\text { spesies }\end{array}$} \\
\hline & & 1 & 2 & 3 & 4 & 5 & 6 & 7 & 8 & 9 & 10 & \\
\hline 1 & Zizina otis & 3 & 1 & - & - & - & - & - & - & - & - & 4 \\
\hline 2 & Junonia almana & 1 & & - & - & 1 & - & - & - & - & - & 2 \\
\hline 3 & Neptis hylas & 6 & 2 & - & - & - & - & - & - & 1 & 2 & 11 \\
\hline 4 & $\begin{array}{l}\text { Agraulis } \\
\text { vanillae }\end{array}$ & & - & - & - & - & - & - & 1 & - & - & $\mathbf{1}$ \\
\hline 5 & M. janardana & 47 & 9 & 3 & 4 & - & - & - & - & - & 2 & 65 \\
\hline 6 & Eurema alitha & 4 & 18 & 8 & 27 & 15 & 28 & 5 & 5 & 18 & 8 & 136 \\
\hline 7 & Appias olferna & 1 & 5 & 2 & 18 & - & - & - & - & - & 11 & 37 \\
\hline 8 & $\begin{array}{l}\text { Catopsilia } \\
\text { pomona }\end{array}$ & 3 & - & - & - & - & - & 1 & 1 & - & 8 & 13 \\
\hline 9 & Melanitis leda & 4 & 6 & 6 & 7 & 6 & 14 & 11 & 8 & 4 & 3 & 69 \\
\hline 10 & $\begin{array}{l}\text { Hypolimnas } \\
\text { bolina }\end{array}$ & 6 & - & - & - & 1 & - & - & - & 2 & 3 & 12 \\
\hline 11 & D. bisaltide & - & - & - & 1 & - & - & - & 1 & 1 & - & 3 \\
\hline 12 & G. agamemnon & - & - & - & - & - & - & - & - & 2 & - & 2 \\
\hline 13 & P. aristolochiae & - & - & - & - & - & 1 & - & - & - & - & 1 \\
\hline 14 & Junonia atlites & - & - & 2 & - & - & - & - & - & - & - & 2 \\
\hline 15 & $\begin{array}{l}\text { Catopsilia } \\
\text { scylla }\end{array}$ & - & - & - & - & - & - & 1 & - & - & - & 1 \\
\hline
\end{tabular}




\begin{tabular}{|c|c|c|c|c|c|c|c|c|c|c|c|c|}
\hline 16 & Leptosia nina & 1 & - & 3 & 3 & 1 & 1 & 3 & 1 & 5 & - & 18 \\
\hline 17 & \begin{tabular}{|l|} 
Caltoris \\
bromus
\end{tabular} & 1 & - & 1 & 2 & - & 11 & 3 & 2 & 7 & 5 & 32 \\
\hline 18 & Junonia orithya & - & - & - & - & - & - & - & - & 3 & - & 3 \\
\hline 19 & $\begin{array}{l}\text { Elymnias } \\
\text { nesaea }\end{array}$ & - & - & 1 & - & - & - & - & - & - & - & 1 \\
\hline 20 & $\begin{array}{l}\text { Tanaecia } \\
\text { palguna }\end{array}$ & - & - & - & - & - & - & - & - & 5 & - & 5 \\
\hline 21 & Oriens gola & - & - & - & - & - & - & - & - & 1 & 1 & 2 \\
\hline 22 & \begin{tabular}{|l|} 
Papilio \\
demoleus
\end{tabular} & - & - & - & - & - & 1 & - & - & - & - & 1 \\
\hline 23 & \begin{tabular}{|l} 
Papilio \\
memnon
\end{tabular} & - & - & - & - & - & - & - & - & 2 & - & 2 \\
\hline $\begin{array}{l}\text { Jun } \\
\text { Selt }\end{array}$ & $\begin{array}{l}\text { lah Spesies } \\
\text { Iruh }\end{array}$ & 77 & 41 & 26 & 62 & 24 & 56 & 24 & 19 & 51 & 43 & \\
\hline
\end{tabular}

Jumlah spesies yang ditemukan pada setiap stasiun kemudian dilakukan perhitungan indek kergamannya dengan mengunakan rumus menurut Shannon-Wienner.
Hasil perhitungan indek keanekaragaman spesies kupu kupu di bantara sungai batanghari dapat dilihat pada tabel 2 .

Tabel 2. Nilai Indeks Keanekaragaman Kupu-kupu di Bataran Sungai Batanghari Kota Metro

\begin{tabular}{|c|c|c|}
\hline $\begin{array}{c}\text { Stasuin } \\
\text { Pengamatan }\end{array}$ & $\mathrm{H}^{\prime}=-\sum$ ni/N log ni/N & Keterangan \\
\hline 1 & 0,638 & Rendah \\
\hline 2 & 0,633 & Rendah \\
\hline 3 & 0,790 & Rendah \\
\hline 4 & 0,632 & Rendah \\
\hline 5 & 0,445 & Rendah \\
\hline 6 & 0,534 & Rendah \\
\hline 7 & 0,592 & Rendah \\
\hline 8 & 0,676 & Rendah \\
\hline 9 & 0,888 & Rendah \\
\hline 10 & 0,848 & Rendah \\
\hline
\end{tabular}


Tabel 3. Kekerabatan ordo lepidoptera (kupu-kupu) di Bantaran Sungai Batanghari Kota Metro

\begin{tabular}{|c|c|c|c|c|c|}
\hline Filum & Class & Ordo & Family & Genus & Spesies \\
\hline \multirow{24}{*}{$\begin{array}{l}\frac{D}{2} \\
\frac{0}{0} \\
\frac{0}{0} \\
0 \\
0\end{array}$} & \multirow{24}{*}{$\begin{array}{l}\vec{\nabla} \\
\tilde{D} \\
\stackrel{\Omega}{\theta}\end{array}$} & \multirow{24}{*}{$\frac{8}{0}$} & \multirow{4}{*}{ Papilionidae } & \multirow[b]{2}{*}{ Papilio } & Papilio memnon \\
\hline & & & & & $\begin{array}{l}\text { Papilio } \\
\text { demoleus }\end{array}$ \\
\hline & & & & Pachliopta & P. aristolochiae \\
\hline & & & & Graphium & G. agamemnon \\
\hline & & & & & \\
\hline & & & \multirow{11}{*}{ Jymphalidae } & \multirow{3}{*}{ Junonia } & Junonia almana \\
\hline & & & & & Junonia orithya \\
\hline & & & & & Junonia atlites \\
\hline & & & & Neptis & Neptis hylas \\
\hline & & & & Agraulis & Agraulis vanillae \\
\hline & & & & Mycalesis & $\begin{array}{l}\text { Mycalesis } \\
\quad \text { Janardana }\end{array}$ \\
\hline & & & & Elymnias & Elymnias nesaea \\
\hline & & & & Melaniti & Melanitis leda \\
\hline & & & & Hypolimnas & $\begin{array}{c}\text { Hypolimnas } \\
\text { bolina }\end{array}$ \\
\hline & & & & Doleschallia & D. bisaltide \\
\hline & & & & Tanaecia & $\begin{array}{l}\text { Tanaecia } \\
\text { palguna }\end{array}$ \\
\hline & & & \multirow{5}{*}{ Pieridae } & Eurema & Eurema alitha \\
\hline & & & & Appias & Appias olferna \\
\hline & & & & \multirow[t]{2}{*}{ Catopsilia } & $\begin{array}{c}\text { Catopsilia } \\
\text { pomona }\end{array}$ \\
\hline & & & & & Catopsilia scylla \\
\hline & & & & Leptosia & Leptosia nina \\
\hline & & & \multirow{2}{*}{ Hesperiidae } & Oriens & Oriens gola \\
\hline & & & & Caltoris & Caltoris bromus \\
\hline & & & Lycaenidae & Zizina & Zizina otis \\
\hline
\end{tabular}




\section{PEMBAHASAN}

Dari hasil penelitian yang telah dilakukan didapatkan sebanyak 23 jenis kupu-kupu dari 5 Familia terdiri dari 4 species dari Familia Papilionidae yaitu Papilio memnon, Papilio demoleus, Pachliopta aristolochiae, dan Graphium agamemnon. 11 species dari Familia Nymphalidae yaitu Junonia almana, Junonia orithya, Junonia atlites, Neptis hylas, Agraulis vanillae, Mycalesis Janardana, Elymnias nesaea, Melanitis leda, Hypolimnas bolina, Doleschallia bisaltide, dan Tanaecia palguna. 5 species dari Familia Pieridae yaitu Eurema alitha, Appias olferna, Catopsilia pomona, Catopsilia scylla, dan Leptosia nina. 2 species dari Familia Hesperiidae yaitu Oriens gola, Caltoris bromus dan 1 species dari Familia Lycaenidae yaitu Zizina otis.

Spesies paling banyak ditemukan jumlah spesies adalah di stasiun 1 dengan jumlah 77 ekor Pada stasiun 1 merupakan habitat yang didominasi tumbuhan akasia dan rumput dengan spesies yang paling banyak ditemukan adalah Mycalesis janardana. Menurut Peggie (2006) spesies Mycalesis janardana suka pada habitat daerah terbuka berbatasan dengan hutan hujan sekunder serta kebun desa di kawasan hutan dan memiliki perilaku terbang rendah dan sering ditemukan bersembunyi pada semak belukar.

Pada total area stasiun pengamatan spesies yang paling banyak ditemukan adalah Eurema alitha sebanyak 136 ekor, Spesies Eurema alitha merupakan kupu-kupu yang berhabitat pada daerah berumput yang terbuka, tempat yang basah atau genangan air serta berperilaku memiliki kebiasaan berkumpul dalam kelompok-kelompok kecil. Eurema alitha juga merupakan kupu-kupu yang suka bermigrasi (Peggie, 2006).

Jumlah spesies yang ditemukan pada setiap stasiun pengamatan kemudian dilakukan perhitungan indek kergamannya dengan mengunakan rumus menurut Shannon-Wienner. Hasil perhitungan indek keanekaragaman spesies kupu kupu di bantaran sungai batanghari didapatkan nilai indek keragaman tertinggi pada stasium 9 dengan nilai 0,888 sedangkan nilai indek keragaman yang paling rendah yaitu pada stasiun pengamatan 5 yaitu 0,445 . Berdasarkan indeks keanekaragaman jenis tersebut hasil penelitian keragaman kupu-kupu di bataran sungai Batanghari Kota Metro dikategorikan adalah sedikit atau rendah karena memiliki nilai Nilai $\mathrm{H}^{1}<1$. Menurut Fitriana (2006) nilai indek dengan Nilai $\mathrm{H}^{1}<1$ adalah keragaman rendah, miskin, produktivitas sangat rendah sebagai indikasi adanya tekanan yang berat dan ekosistem tidak stabil. Berdasarkan indeks keanekaragaman jenis menurut Shannon-Wienner didefinisikan sebagai berikut :

1. Nilai $\mathrm{H} 1>3$ menunjukan bahwa keanekaragaman spesies pada suatu transek adalah melimpah tinggi.

2. Nilai $\mathrm{H} 11 \leq \mathrm{H} 1 \leq 3$ menunjukan bahwa keanekaragaman spesies pada transek adalah sedang melimpah.

3. Nilai $\mathrm{H} 1<1$ menunjukan bahwa keanekaragaman spesies pada suatu tarnsek adalah sedikit atau rendah.

Peranan kupu-kupu sangat penting dalam suatu ekosistem kupukupu karena membantu penyerbukan tanaman berbunga, sehingga proses perbanyakan tumbuhan secara alamiah dapat berlangsung (Peggie \& Amir 
2006). Menurut Widhiono (2004) bahwa kelimpahan kupu-kupu di empat tipe habitat yaitu hutan alam, hutan tanaman, hutan wisata, dan hutan pertanian. Modifikasi habitat menjadi salah satu hal yang harus diperhatikan untuk mempertahankan kelimpahan kupu-kupu (Subahar \& Yuliana 2010). Kondisi lingkungan makhluk hidup ini sangat beragam. Kondisi lingkungan yang beragam tersebut menyebabkan jenis makhluk hidup yang menempatinya beragam pula. Keanekaragaman seperti ini disebut sebagai keanekaragaman tingkat ekosistem.

Faktor abiotik yang mempengaruhi faktor biotik di antaranya adalah iklim, tanah, air, udara, suhu, angin, kelembapan, cahaya, mineral, dan tingkat keasaman. Variasi faktor abiotik menimbulkan kondisi berbeda pada setiap ekosistem. Untuk mengetahui adanya keanekaragaman hayati pada tingkat ekosistem, dapat dilihat dari satuan atau tingkatan organisasi kehidupan di tempat tersebut. Kondisi ekosistem di bantaran sungai Batanghari Kota Metro relatif homogen dengan hutan tanaman dan pertanian sehingga keragaman spesies di tempat tersebut dikategorikan rendah.

Jumlah kupu-kupu secara umum sangat tergantung pada pengelolaan suatu daerah. Daerah yang dilindungi (protected area) memiliki keanekaragaman spesies kupu-kupu lebih tinggi daripada daerah yang sudah mengalami alih fungsi lahan. Banyak penelitian menunjukkan bahwa habitat kupu kupu dengan jumlah pakan yang tersedia cukup akan diikuti juga dengan keanekaragaman kupukupu yang tinggi (Thomas et al. 2004). Kenekargaman kupu-kupu di bantaran sungai Batanghari Kota Metro akan meningkat jika ditambahkan lagi berbagai jenis tanaman yang beranekaragam sehingga jumlah keragaman kupu-kupupun akan betambah sesuai dengan fungsi kupukupu sebagai agen indikator dan penyeimbang ekosistem.

\section{KESIMPULAN DAN SARAN \\ Kesimpulan}

Keragaman kupu-kupu Di

Bantaran Sungai Batanghari Kota Metro dikategorikan sedikit atau rendah karena memiliki nilai Nilai $\mathrm{H}^{1}<$ 1 , dengan spesies yang paling dominan adalah Eurema alitha sebanyak 136 ekor. Dari hasil penelitian keanekaragaman kupu-kupu tersebut dapat digunakan sebagai sumber belajar biologi SMA pada materi keanekaragaman.

\section{Saran}

Perlu dilakukan penelitian lebih lanjut tentang habitat dan jenis tumbuhan yang digunakan untuk siklus hidup kupu-kupu serta studi dampak lingkungan terhadap domiasi spesies tertentu pada habitat tertentu.

\section{DAFTAR RUJUKAN}

Dahelmi, Salmah ,S. \& Primadalvi, I. 2010. Kupu-kupu (butterflies) di Pulau Marak, Kabupaten Pesisir Selatan, Sumatera barat. Imran M, Nana, Putera (Eds). 2010. Prosiding, seminar dan rapat tahunan BKS-PTN Wilayah Barat ke-21 10-12 Mei 2010. Padang: 8 hlm.

Fitriana Y. R. 2006. Keanekaragaman dan Kemelimpahan Makrozoobentos di Hutan Mangrove Hasil Rehabilitasi Taman Hutan Raya Ngurah Rai Bali. BIODIVERSITAS. ISSN: 1412-033X. 
Gillott, C. 2005. Entomology Third Edition. Publised by Springer. Dordrecth: xvii +834 hlm.

Koh K. P., \& Sodhi N.S. 2004. Importance of reverse, fragments and parks for butterfly conservation in a tropical urban lanscape. Ecological Applications. 14 (6): 1695-1708.

Koneri, R. dan Saroyo. 2012. Distribusi dan keanekaragaman kupu-kupu (lepidoptera) Di gunung manado tua, Kawasan taman nasional laut bunaken, sulawesi utara. jurnal bumi lestari, volume 12 no. 2, hlm. $357-365$

Nworo dan Anwar, P. 2003. Metode survei dan Pemantauan Populasi Satwa. Bogor: CV Putra Nusantara penelitian Biologi, LIPI

Peggie D., dan Amir M. 2006. Panduan Praktis Kupu-kupu di Kebun Raya Bogor. Bogor: Bidang Zoologi Pusat

PEI-Pusat. 2011. Pusat informasi kupu-kupu Sumatera. Perhimpunan Entomologi Indonesia: $\quad 1 \quad \mathrm{hlm}$. www.rokan.org, 19-05-2011, pk 03:03 WIB.

Salmah, S, Abbas,I., \& Dahelmi. 2002. Кири-kири Papilionidae di Taman Nasional Kerinci Seblat. KEHATI.

Departemen

Kehutanan. Taman Nasional Kerinci Seblat.
Soekardi, H. 2007. Кири-kири di kampus Unila. Penerbit Universitas Lampung. Lampung: $52 \mathrm{hlm}$.

Subahar, T.S.S., \& Yuliana, A. 2010. Butterfly diversity as a data base for the Development plant of Butterfly Garden at Bosscha Observatory, Lembang, West Java. Biodiversitas 11 (1): 2428.

Suhara. 2009. Ornitophtera goliath; Si Cantik dari Papua. Jurusan Pendidikan Biologi Fakultas Pendidikan Matematika dan Ilmu Pendidikan Alam Universitas Pendidikan Indonesia

Sundufu, A.J., \& Dumbuya, R. 2008. Habitat preferences of butterflies in the Bumbuna forest, Northern Sierra Leone. Journal of Insect Science. Vol. 8: 1-17.

Thomas, J.A., Telfer, M.G., Roy, D.B., Preston, C.D., Greenwood, J.J.D., Asher, J., Fox, R., Clarke, R.T., \& Lawton, J.H. 2004. Comparative losses ofbritish butterflies, birds, and plants and the global extinction. Science. 303: 1879-1881.

Widhiono, I. 2004. Dampak modifikasi hutan terhadap keragaman hayati kupu-kupu di gunung Slamet Jawa Tengah. 2004. Biosfera 21 (3):89- 